\title{
EVAPORATION STUDY AT \\ WARM SPRINGS RESERVOIR, \\ OREGON
}

\author{
Prepared \\ in cooperation with \\ Oregon State Engineer
}

OPEN-FILE REPORT

U.S. Department of the Interior

Geological Survey

Water Resources Division

Portland, Oregon

1968 
UNITED STATES

DEPARTMENT OF THE INTERIOR

GEOLOGICAL SURVEY

EVAPORATION STUDY AT WARM SPRINGS RESERVOIR, OREGON

By D. D。 Harris

Prepared in cooperation with the Oregon State Engineer

Open-file report

Portland, Oregon

January 1968 
Abstract -

Introduction -... 1

Purpose and scope - 1

Acknowledgments -

Description of the area

Location and physiography -

C1imate -... 4

Study methods

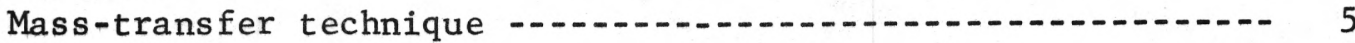

Water-budget contro1

Available data -

Instrumentation -... 7

Evaluation of results

Conclusions and recommendations -..... 15

References -

\section{ILLUSTRATIONS}

Figure 1. Location map of Warm Springs Reservoir

2. Photograph of raft carrying anemometer and thermograph equipment -..... 8

3. Photograph of stilling well attached to back face of dam to record lake leve1 .....

4. Graph showing relation between water-budget evaporation and the product $u\left(e_{0}-e_{a}\right)$ for periods in 1964-66, and showing the computed mass-transfer

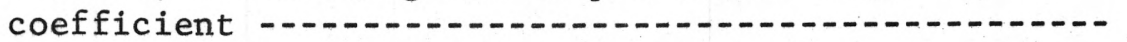

5. Graph showing relation between water-budget evaporation and the product $u\left(e_{o}-e_{a}\right)$, for periods in 1964, and showing computed mass-transfer coefficient -.-.-.-.---

6. Graph showing relation between water-budget evaporation and the product $u\left(e_{o}-e_{a}\right)$ for periods in 1965, and showing the computed mass-transfer coefficient -.--.-

7. Graph showing relation between water-budget evaporation and the product $u\left(e_{o}-e_{a}\right)$ for periods in 1966, and showing the computed mass-transfer coefficient -...-.-

TABLES

Table 1. Calibration data

2. Evaporation, in inches, from 1 and pan and from masstransfer method for selected months in 1964 
By D. D. Harris

ABSTRACT

The mass transfer-water budget method of computing reservoir evaporation was tested on Warm Springs Reservoir, whose contents and surface area change greatly from early spring to late summer. The mass-transfer coefficient computed for the reservoir is two to three times greater than expected and results in a computed evaporation much greater than that from a land pan. Because of the remoteness of the area, the recommended study technique was modified, which could have reduced the accuracy of the results.

\section{INTRODUCTION}

\section{Purpose and Scope}

Where evaporation from irrigation reservoirs is large, reliable estimates of evaporation are essential to the efficient management and equitable distribution of the water. Water losses from irrigation reservoirs in such circumstances can amount to a large part of the water stored. Evaporation from reservoirs in Oregon has been estimated primarily on the basis of evaporation measured in standard land pans adjusted by application of a pan-to-lake coefficient defined by the U.S. Weather Bureau. When a single regional coefficient is applied to the observed data, the land pan may give a fair approximation of reservoir evaporation. However, seasonal and short-term variations in the evaporation coefficient may occur throughout the year and from year to year. Also, local anomalies can occur where the regional pan coefficient does not apply. Therefore, an improved method is needed to estimate more accurately the evaporation from highly regulated irrigation reservoirs.

A simple method for determining evaporation based on the masstransfer theory had been derived from evaporation studies at Lake Hefner in Oklahoma. Because this method had given satisfactory results at Lake Mead and many other reservoirs, it seemed a practical means of improving evaporation estimates from highly regulated irrigation reservoirs in Oregon. During 1961-63 a cursory study was made at Lake Abert, a closed lake in south-central Oregon, using the mass-transfer 
technique in conjunction with a water-budget study. Upon completion of the Lake Abert study, the Geological Survey and the Oregon State Engineer decided to try the same technique at an irrigation reservoir.

A pilot study was conducted on Warm Springs Reservoir in southeastern Oregon, where evaporation is very high. The reliability of the results of the study depended on defining accurately a mass-transfer coefficient for the reservoir. The coefficient can be computed from a relationship between parameters relating to water-vapor exchange between the water surface and the atmosphere, and evaporation computed from a water budget of the reservoir. In contrast to Lake Abert, where evaporation is as much as 90 percent of the water budget, evaporation from Warm Springs Reservoir rarely exceeds 20 percent of the water budget. Therefore, the main problem of the study was to define the large elements of the water budget (inflow, outflow, change in storage) accurately so as to minimize errors in the residual element, evaporation.

The purpose of this study was to evaluate the use of the mass transfer-water budget technique for improving evaporation estimates at Warm Springs Reservoir. It was a test of the accuracy of determining the water budget and of measuring the parameters relating to vapor exchange. The evaluation tests the adaptability of the technique in a practical field situation. The evaluation is not intended to be a test of the validity of the mass-transfer theory. Difficult access to the remote study site affected the accuracy of the data collected, and this restriction is reflected in the results.

\section{Acknowledgments}

The investigation was financed cooperatively by the Geological Survey and the Oregon State Engineer. The report was prepared in the Portland District of the Geological Survey, Water Resources Division, under the supervision of Stanley F. Kapustka, district chief.

Assistance in collecting field data was provided by Vale Irrigation District, U.S. Bureau of Land Management, and local residents.

\section{DESCRIPTION OF THE AREA}

\section{Location and Physiography}

Warm Springs Reservoir is on the Malheur River, 40 miles east of Burns in southeastern Oregon (fig. 1). The reservoir was created by the construction of Warm Springs Dam, a concrete arch dam, with storage beginning in 1919. At maximum pool level the reservoir is about 6 miles long in a general north-northwest to south-southeast direction and up to $1 \frac{1}{2}$ miles wide. The drainage area above the dam is approximately 


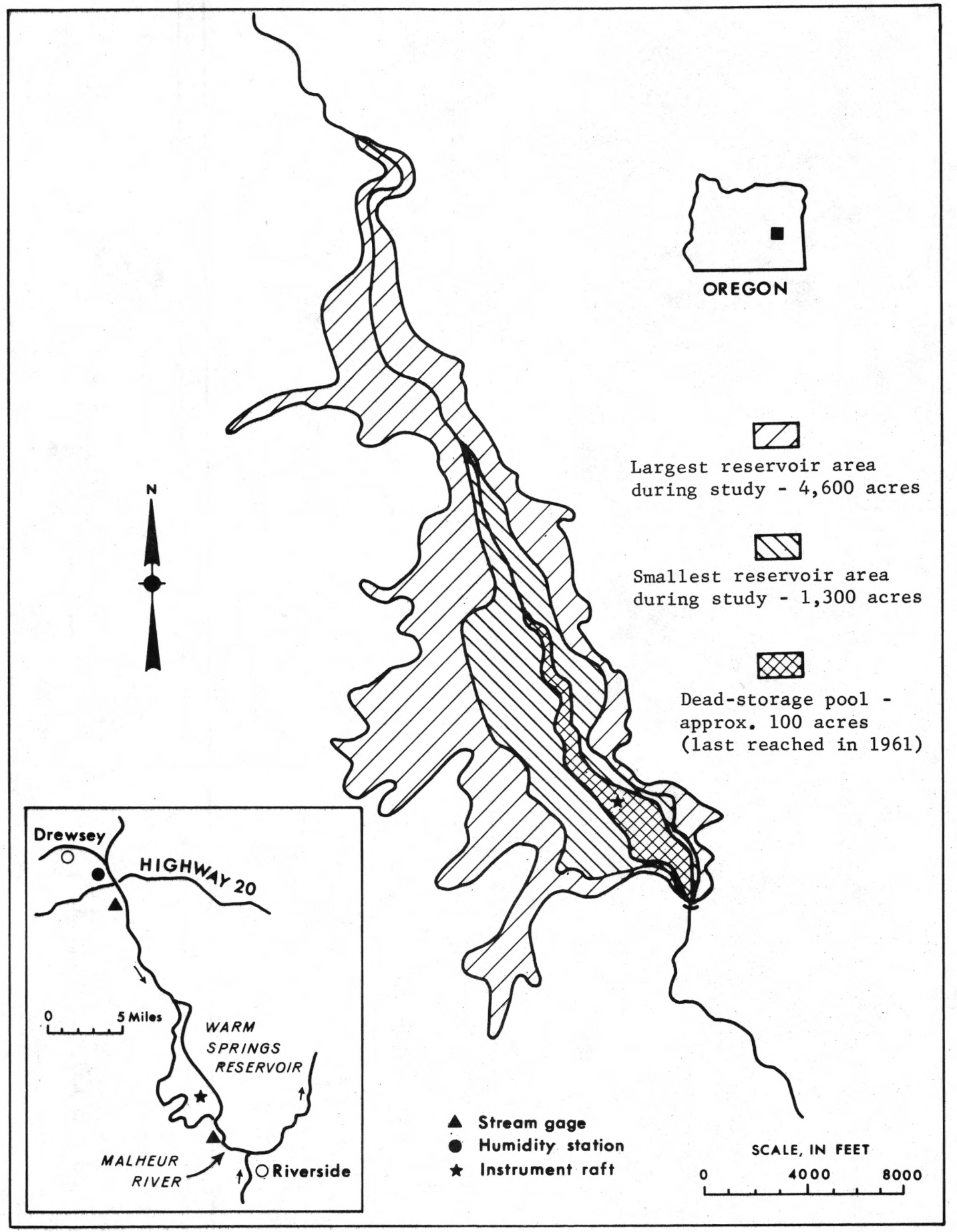

Figure 1.--Location map of Warm Springs Reservoir. 
1,100 square miles. The reservoir area at ful1 reservoir 1 evel (elev $3,406 \mathrm{ft}$ ) is about 4,600 acres, and the area at the lowest level observed during the 3-year evaporation study was 1,300 acres. The boundaries of high pool and low pool during the study period are shown in figure 1. Storage of water normally begins in the fall, and the pool is maintained at a high level until late spring or early summer, when releases in excess of inflow furnish irrigation water for downstream users.

The drainage basin is primarily a mountainous area of folded and faulted volcanic and sedimentary rocks. Altitudes range from about 3,350 feet near the Warm Springs Dam to 9,600 feet in the Strawberry Mountains. The entire area is dissected by erosion, and moderate to steep slopes characterize most of the basin.

The reservoir is in the wide, flat valley bottom that prior to the construction of the dam was irrigated by ditches from the Malheur River. According to R. E. Corcoran of the Oregon State Department of Geology and Mineral Industries (written commun., 1965), the rocks around the reservoir are primarily tuffaceous sediments of Pliocene age. These sediments also form the hills along the east side of the reservoir. The narrow gorge at the dam is cut in Miocene basalt. Borings made at the damsite prior to the construction of the dam show that the valley bottom at the damsite was underlain by up to 17 feet of sand and boulders resting on basalt bedrock (Whistler and Lewis, 1916, p. 60-88).

\section{Climate}

The climate in the vicinity of Warm Springs Reservoir is semiarid, and a long-term average annual precipitation of 8.3 inches has been recorded at a weather station 0.4 mile downstream from the dam. In parts of the mountainous area of the drainage basin, the annual precipitation averages nearly four times that amount. Much of the precipitation in the reservoir area falls as snow from November to April, but snow may fall on the surrounding mountains any month of the year. Cloudbursts are not uncommon in the summer.

Temperatures in the vicinity of the reservoir range from an average of about $25^{\circ} \mathrm{F}$ in January to an average of about $72^{\circ} \mathrm{F}$ in July. During summer, maximum temperatures in the afternoons may exceed $100^{\circ} \mathrm{F}$, but at night the summer temperatures generally drop to the low fifties and forties.

Prevailing winds on the reservoir are westerly.

According to Kohler, Nordenson, and Baker (1959, p1s. 1, 2), the average annual evaporation from class A pans in this area is 55 inches and the average annual lake evaporation is 40 inches. 


\section{STUDY METHODS}

The method proposed for studying evaporation at Warm Springs Reservoir required that a relationship be developed between the parameters in the mass-transfer equation and the evaporation element of the water budget of the lake. The slope of the line of relation is the masstransfer coefficient. A positive or negative intercept of the line of relation on the evaporation axis indicates leakage or unmeasured inflow, respectively.

\section{Mass-Transfer Technique}

The mass-transfer technique involves the use of a simple quasiempirical equation derived from studies at Lake Hefner. The equation is:

$$
E=N u\left(e_{0}-e_{a}\right)
$$

in which

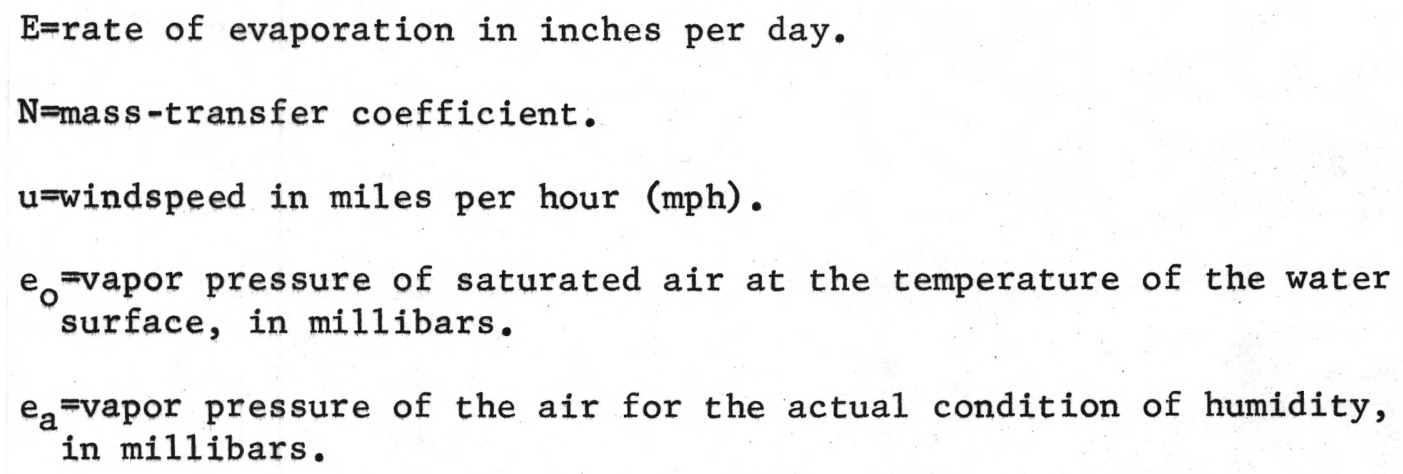

It is evident from the evaporation equation that evaporation is proportional to the product of windspeed, $u$, and vapor-pressure difference, $\mathrm{e}_{\mathrm{o}}-\mathrm{e}_{\mathrm{a}} \cdot$

Windspeed, $u$, is obtained from an anemometer mounted 2 meters above the water surface on a raft at midreservoir.

Vapor pressure, $e_{o}$, is the vapor pressure of saturated air at the temperature of the water surface of the reservoir. The water-surface temperature is obtained from a thermograph on the raft.

Vapor pressure, $e_{a}$, is the humidity of the incoming air as measured by a hygrothermograph, usually on the prevailing windward side of the reservoir. 
The mass-transfer coefficient, $\mathrm{N}$, is the ratio of measured evaporation, $E$, to the product of windspeed, $u$, and vapor-pressure difference, $\left(e_{0}-e_{a}\right)$. The coefficient is most precisely computed by first making an energy-budget determination of evaporation for a year or more and then dividing the energy-budget evaporation, $\mathrm{E}_{\mathrm{eb}}$, by the product, $\mathrm{u}\left(\mathrm{e}_{\mathrm{o}}-\mathrm{e}_{\mathrm{a}}\right)$. However, the energy-budget method is costly and necessitates the use of many precise instruments, which require frequent servicing. A simpler but less accurate technique for determining the mass-transfer coefficient is to compute it from the relation between evaporation from the water budget, $E_{w b}$, and $u\left(e_{o}-e_{a}\right)$. In using the latter method, the accuracy of the computed mass-transfer coefficient depends on the accuracy of the various evaporation losses computed from the water budget. Because $\mathrm{E}_{\mathrm{wb}}$ is computed as the residual of measured inflow, outflow, and change in reservoir storage, it may also include some unmeasured seepage into or out of the reservoir.

For reservoirs similar in size to Warm Springs, mass-transfer coefficients between about 0.002 and 0.003 for computing evaporation in inches have been obtained (Harbeck, 1962, p. 104).

\section{Water-Budget Contro1}

Evaporation is computed as the residual from a measured water budget. Realiability of the evaporation value obtained from a budget depends on the accurate measurement of each budget element. Therefore, to minimize the effect of errors in the measured values of inflow, outflow, and storage change, it is desirable that the evaporation be a large part of the budget.

Warm Springs Reservoir was chosen for this study because evaporation at this site represents a larger percentage of the water budget than evaporation from other reservoirs in the State. Also, seepage losses from the reservoir are thought to be negligible because of the apparently impervious basalt "seal" at the damsite. Some seepage 1oss occurs through the dam when the gates are closed, but most of this seepage should find its way back to the river upstream from the outflow gage because bedrock constricts the channel at the gage control. Seepage loss through the closed tunnel gates as measured at the gage is less than 1 cfs (cubic feet per second).

\section{AVAILABLE DATA}

Hydrologic data have been collected in the vicinity of the reservoir for many years. The Weather Bureau operates a precipitation, temperature, and evaporation station 0.4 miles downstream from Warm Springs Dam, and a precipitation and temperature station at Juntura, about 15 miles northeast of the dam. Inflow to the reservoir has been gaged on 
Malheur River near Drewsey since 1920 (drainage area, $910 \mathrm{sq} \mathrm{mi}$ ). Outflow from the reservoir has been gaged continuously since 1920 at a point 1 mile downstream from the dam (drainage area, 1,100 sq $\mathrm{mi}$ ). Except during heavy rains or melting of snow, surface runoff from the intervening drainage area is negligible. Reservoir stages are read periodically by an employee of the Vale Irrigation District. Reservoir storage is determined from a table originally prepared in 1920 by the U.S. Bureau of Reclamation. The table was revised in 1943 by smoothing of differences between defined points in the original table and reevaluating the reservoir capacity at the top of the flashboards on the dam (elev, 3,406 ft).

\section{INSTRUMENTATION}

The mass-transfer study required hydrologic data in addition to that already being collected. Therefore, a raft carrying an anemometer for recording wind velocity and a thermograph for recording the temperature of the water surface of the reservoir (fig. 2) was anchored as near as possible to the middle of the reservoir. The cups of the anemometer were positioned 2 meters above the water surface; the thermograph probe was set one-half inch under the water surface. The raft was positioned closer to the dam than is normally desirable, so that it would remain afloat down to the dead-storage pool level that occasionally occurs in late summer. The location of the raft and the boundary of the dead-storage pool are shown in figure 1.

Air temperature and humidity were measured by a hygrothermograph on the prevailing windward side of the reservoir at a site 10 miles to the northwest (fig. 1) so that the vapor pressure thus computed would be representative of the natural air unmodified by vapor emitted from the reservoir. This measuring site was on a small hill along the right bank of the river and about 150 feet above high-reservoir level.

To obtain an accurate record of the daily changes in lake stage, a stilling well (fig. 3) and stage recorder were installed on the upstream face of the dam.

\section{EVALUATION OF RESULTS}

The factor $u\left(e_{0}-e_{a}\right)$ was plotted against evaporation loss $E_{w b}$, as determined from the water budget of the reservoir (fig. 4). The calibration data used in the plot (table 1) were restricted to average daily values for periods of 4 to 7 days each during 1964-66. To eliminate errors in the water budget due to local variations in precipitation and unknown runoff contributions, days when precipitation occurred were not used in any of the periods. There were many equipment-operation problems, which caused loss of record and further restricted the number of usable plotting periods. 


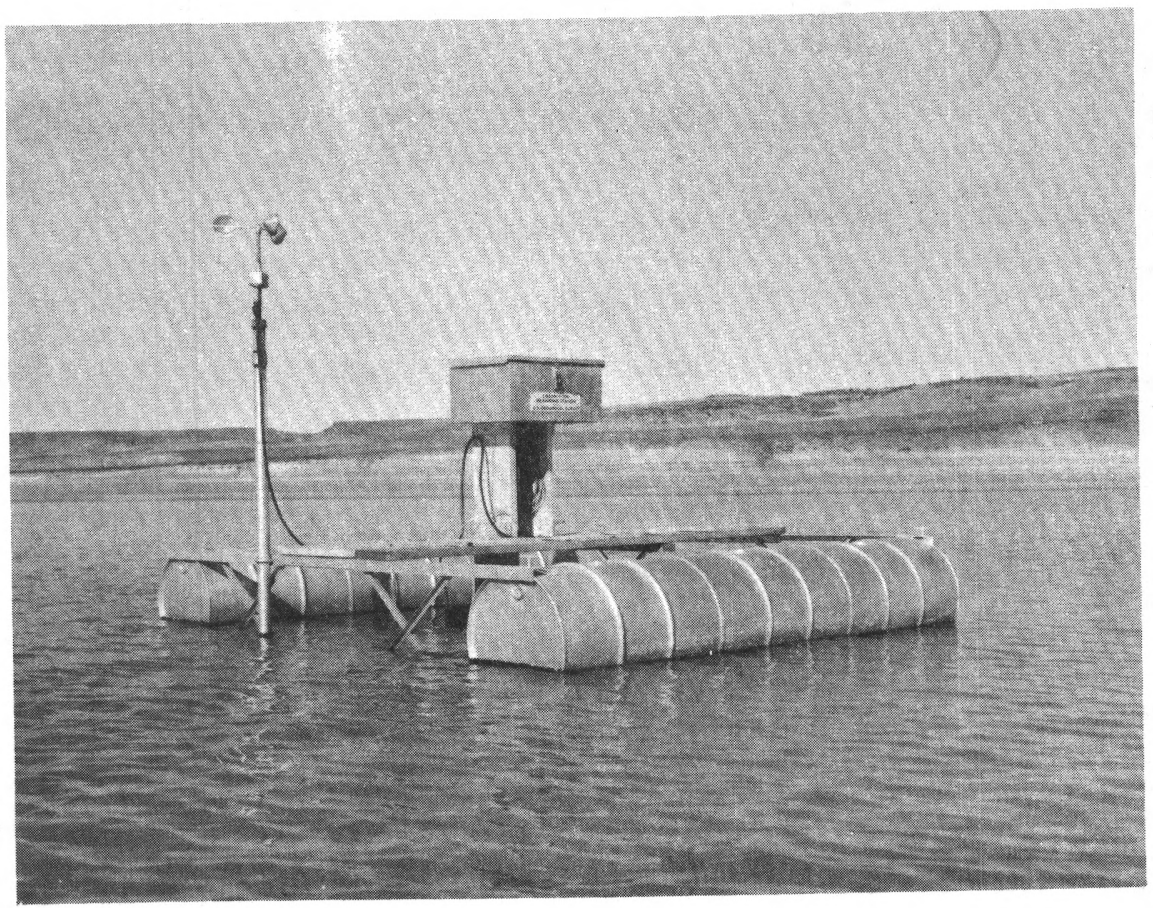

Figure 2.--Raft carrying anemometer and thermograph equipment.

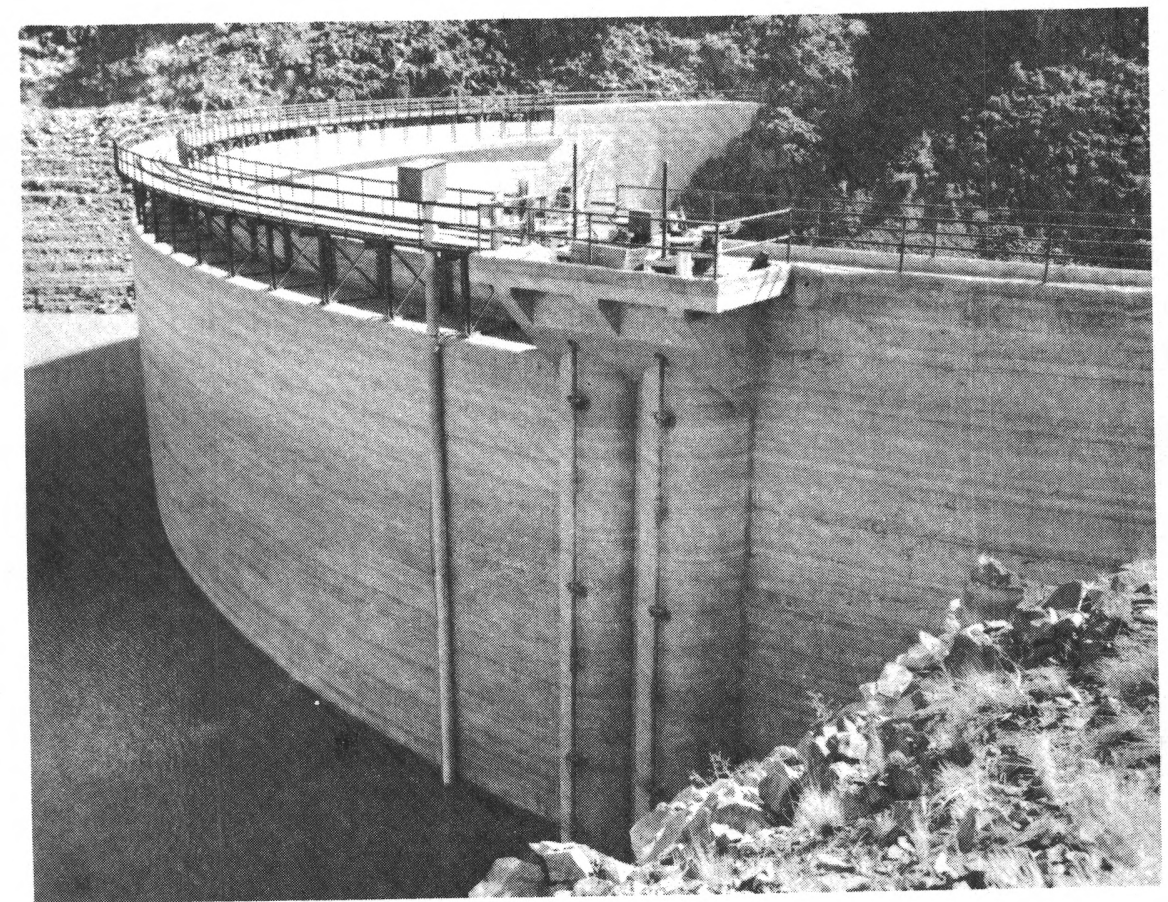

Figure 3.--Stilling well attached to back face of dam to record lake level. 
Tab1e 1.--

\begin{tabular}{|c|c|c|c|c|c|c|c|c|c|}
\hline \multirow[b]{2}{*}{$\begin{array}{l}\text { Num- } \\
\text { ber }\end{array}$} & \multicolumn{2}{|l|}{ Period } & \multirow{2}{*}{$\begin{array}{c}\text { Average } \\
\mathrm{u}\left(\mathrm{e}_{\mathrm{o}}-\mathrm{e}_{\mathrm{a}}\right) \\
\text { (u in miles } \\
\text { per hour, } \\
\mathrm{e} \text { in } \\
\text { millibars) }\end{array}$} & \multirow{2}{*}{$\begin{array}{c}\text { Computed } \\
\text { water-budget } \\
\text { evaporation } \\
\mathrm{E}_{\text {wbl/ / (feet }} \\
\text { per day) }\end{array}$} & \multirow[b]{2}{*}{$\begin{array}{l}\text { Num- } \\
\text { ber }\end{array}$} & \multicolumn{2}{|l|}{ Period } & \multirow{2}{*}{$\begin{array}{c}\text { Average } \\
u\left(e_{o}-e_{a}\right) \\
\text { (u in miles } \\
\text { per hour, } \\
e \text { in } \\
\text { millibars) } \\
\end{array}$} & \multirow{2}{*}{$\begin{array}{c}\text { Computed } \\
\text { water-budget } \\
\text { evaporation } \\
\mathrm{E}_{\text {wb }} \text { // (feet } \\
\text { per day) }\end{array}$} \\
\hline & Dates & $\begin{array}{l}\text { Number } \\
\text { of days }\end{array}$ & & & & Dates & $\begin{array}{l}\text { Number } \\
\text { of days }\end{array}$ & & \\
\hline & $\underline{1964}$ & & & & & 1965 & & & \\
\hline 1 & July $1-4$ & 4 & 84.7 & 0.048 & 18 & May 8-14 - - - & 7 & 21.5 & 0.006 \\
\hline 2 & $7-11 \ldots$ & 5 & 76.7 & .041 & 19 & $15-18 \quad \cdots--$ & 4 & 46.5 & .016 \\
\hline 3 & $12-16-\cdots--$ & 5 & 99.4 & .047 & 20 & $24-27 \quad \ldots-\ldots$ & 4 & 43.9 & .010 \\
\hline 4 & Aug. 9-15 & 7 & 68.7 & .032 & 21 & 29-June 4 -- & 7 & 13.2 & .017 \\
\hline 5 & $16-19-\cdots-\cdots$ & 4 & 109 & .034 & 22 & June $5-8$ & 4 & 20.5 & .004 \\
\hline 6 & $20-23 \quad \ldots-\cdots$ & 4 & 41.3 & .028 & 23 & July 15-21 & 7 & 86.1 & .048 \\
\hline 7 & Sept. $4-7 \quad \ldots-$ & 4 & 47.2 & -.010 & & 1966 & & & \\
\hline 8 & $8-14 \ldots-\cdots$ & 7 & 53.5 & -.010 & 24 & July $4-8 \quad \ldots-$ & 5 & 68.4 & .041 \\
\hline 9 & $15-21 \cdots \cdots$ & 7 & 79.5 & -.013 & 25 & $14-18 \quad \ldots-$ & 5 & 59.6 & .054 \\
\hline 10 & $22-28 \quad \cdots--$ & 7 & 40.6 & -.002 & 26 & $19-23 \quad \ldots-$ & 5 & 84.9 & .037 \\
\hline 11 & $29-0 c t .5--$ & 7 & 55.9 & .028 & 27 & $24-28 \quad \cdots--$ & 5 & 96.0 & .046 \\
\hline 12 & Oct. $9-15 \ldots$ & 7 & 36.8 & -.002 & 28 & Aug. 2-6 -..-- & 5 & 79.3 & .053 \\
\hline 13 & $16-22-\cdots-\cdots$ & 7 & 27.7 & -.008 & 29 & $7-10 \quad \ldots$ & 4 & 82.4 & .048 \\
\hline 14 & $23-29 \quad \ldots-\ldots$ & 7 & 17.6 & -.010 & 30 & $11-17 \quad \cdots$ & 7 & 85.2 & .069 \\
\hline 15 & Nov. $3-9$ & 7 & 15.0 & -.004 & 31 & Sept. $1-4 \quad \ldots-$ & 4 & 30.7 & .014 \\
\hline . & $\underline{1965}$ & & & & 32 & $5-8 \quad---$ & 4 & 47.6 & .016 \\
\hline 16 & Mar. $1-7$ & 7 & 8.8 & -.002 & 33 & $9-12 \quad---$ & 4 & 56.5 & .010 \\
\hline 17 & $8-11-\cdots-1$ & 4 & 1.8 & -.014 & 34 & $16-22$ & 7 & 27.0 & .012 \\
\hline
\end{tabular}

1/ May include some unmeasured seepage or leakage. 
A mass-transfer coefficient of 0.0072 (for evaporation, in inches per day) was computed from the slope of the regression line (fig. 4) by using the least-squares method. A coefficient computed from a graphical solution of the regression was much greater than 0.0072 . The standard error of the least-squares regression is 0.016 feet, which is about 74 percent of the average plotted evaporation value. This means that, on the average, two-thirds of the points plot within 74 percent of the curve. The curve is poorly defined, and the computed coefficient is nearly three times as large as for other lakes or reservoirs of comparable size (Harbeck, 1962, p. 104). A coefficient as large as 0.0072 indicates that either evaporation is nearly three times as large as expected or there is an error in one or more of the factors used to compute evaporation.

The intercept of the regression line indicates ungaged seepage into the reservoir of 8 to $28 \mathrm{cfs}$.

To test the consistency of the coefficient from year to year, separate coefficients were computed by the least-squares method for 1964, 1965, and 1966 (figs. 5, 6, 7). The coefficients for 1964, 1965, and 1966 computed by the least-squares method were $0.0068,0.0071$, and 0.0082 , respectively, which are two to four times as large as expected.

Regressions of $u\left(e_{0}-e_{a}\right)$ versus $E_{w b}$ (evaporation from the water budget), developed by grouping the data by seasons or by high, low, or medium lake level, also were poorly defined and showed no significant changes from the previously computed coefficient values.

A study was made to test the effect of unmeasured bank storage on the evaporation as computed from a water budget. Theoretically, for a falling reservoir the effect of unmeasured bank storage would be to show less than actual evaporation, and for a rising reservoir the effect would be to show more than actual evaporation. Ideally, waterbudget computations of evaporation should be made for periods of no surface inflow or outflow or when inflow and outflow are equal. Unfortunately, in this study, reservoir inflow and outflow were never zero and were rarely equal. Separate regressions of $u\left(e_{o}-e_{a}\right)$ versus $\mathrm{E}_{\mathrm{wb}}$ for a rising reservoir and a falling reservoir showed no noticeable reduction of scatter in plotted points nor a significant change in the computed mass-transfer coefficients.

Table 2 shows a comparison of evaporation from the land pan with that computed by the mass-transfer technique. 


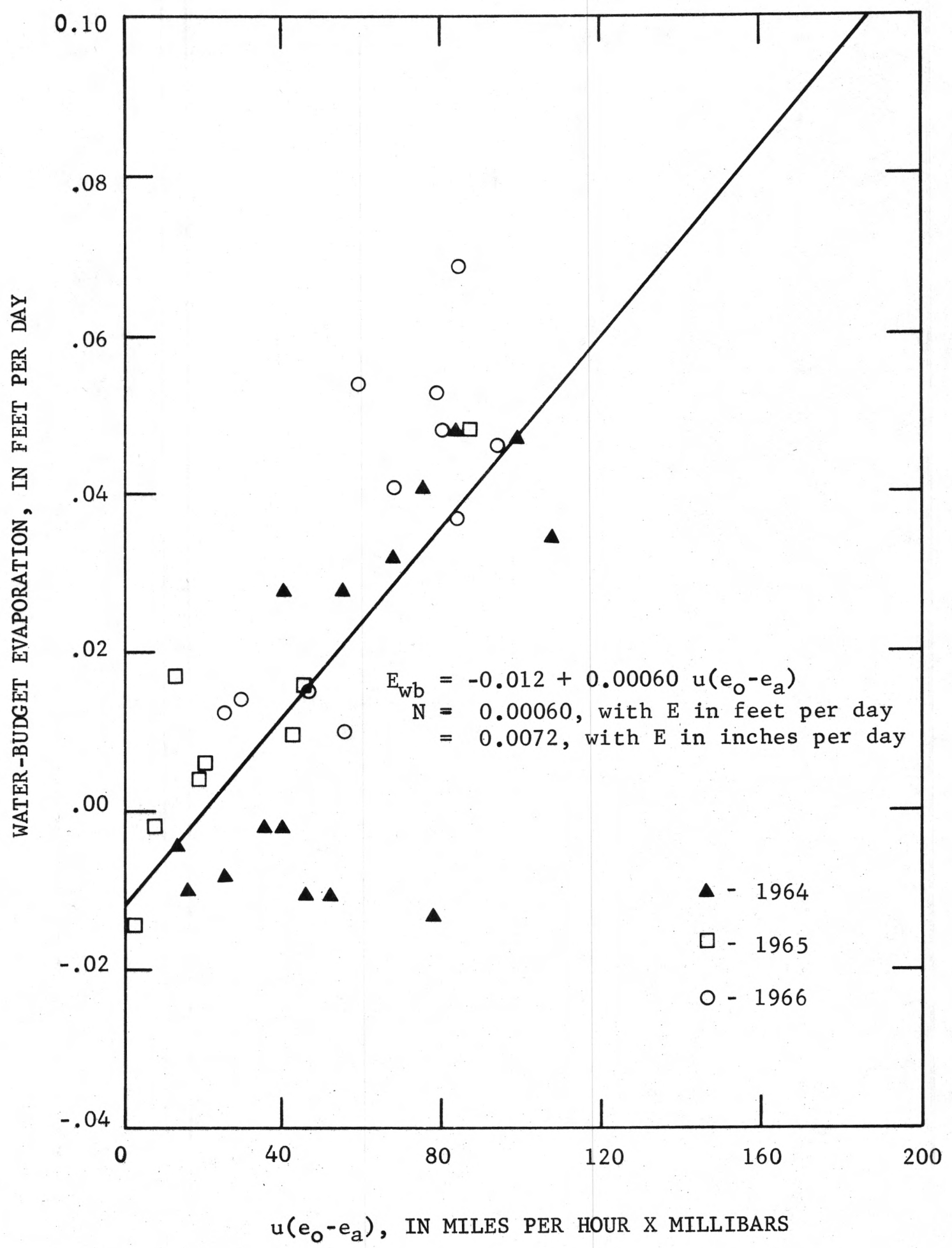

Figure 4.--Relation between water-budget evaporation and the product $u\left(e_{o}-e_{a}\right)$ for periods in 1964-66, and the computed mass-transfer coefficient. 


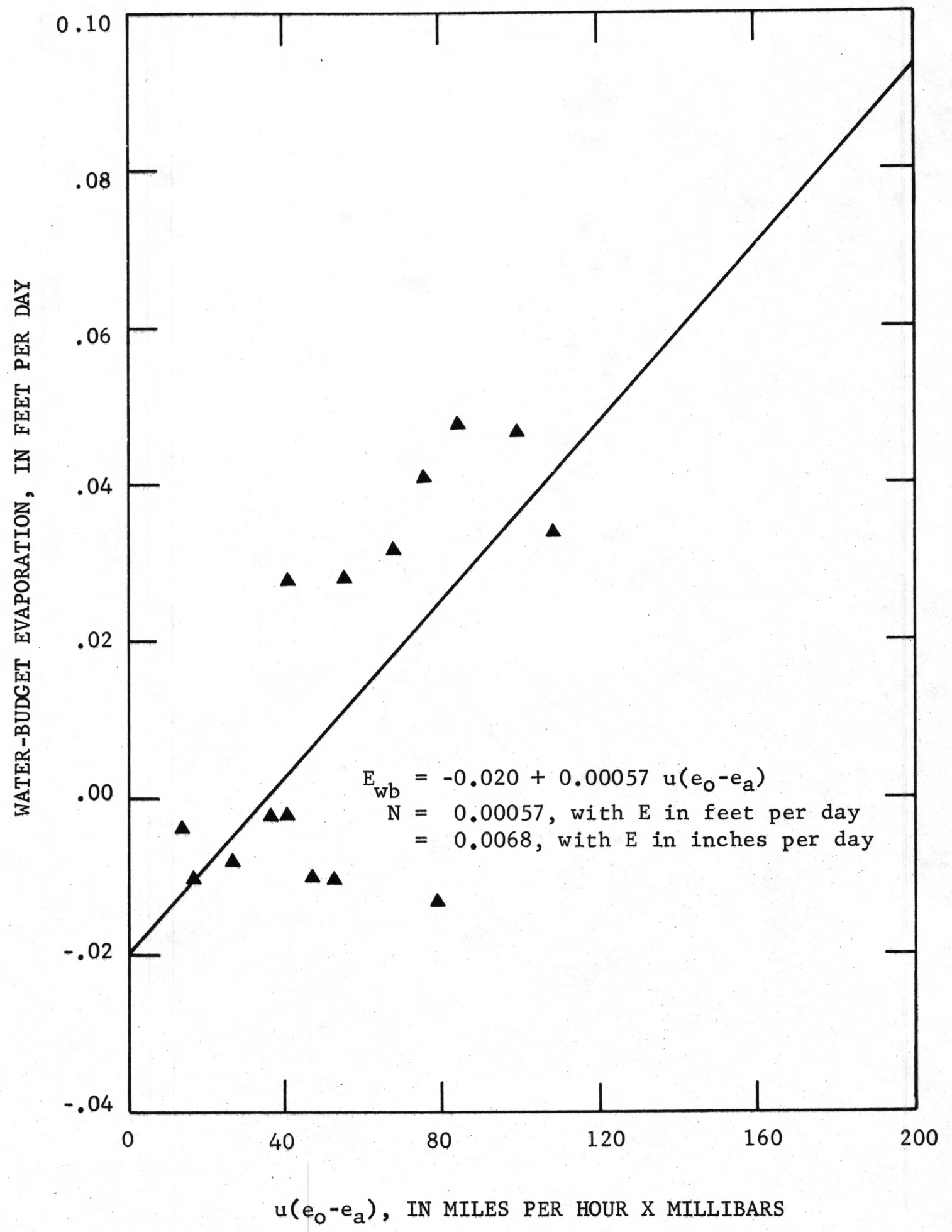

Figure 5.--Relation between water-budget evaporation and the product $u\left(e_{o}-e_{a}\right)$ for periods in 1964, and the computed mass-transfer coefficient. 


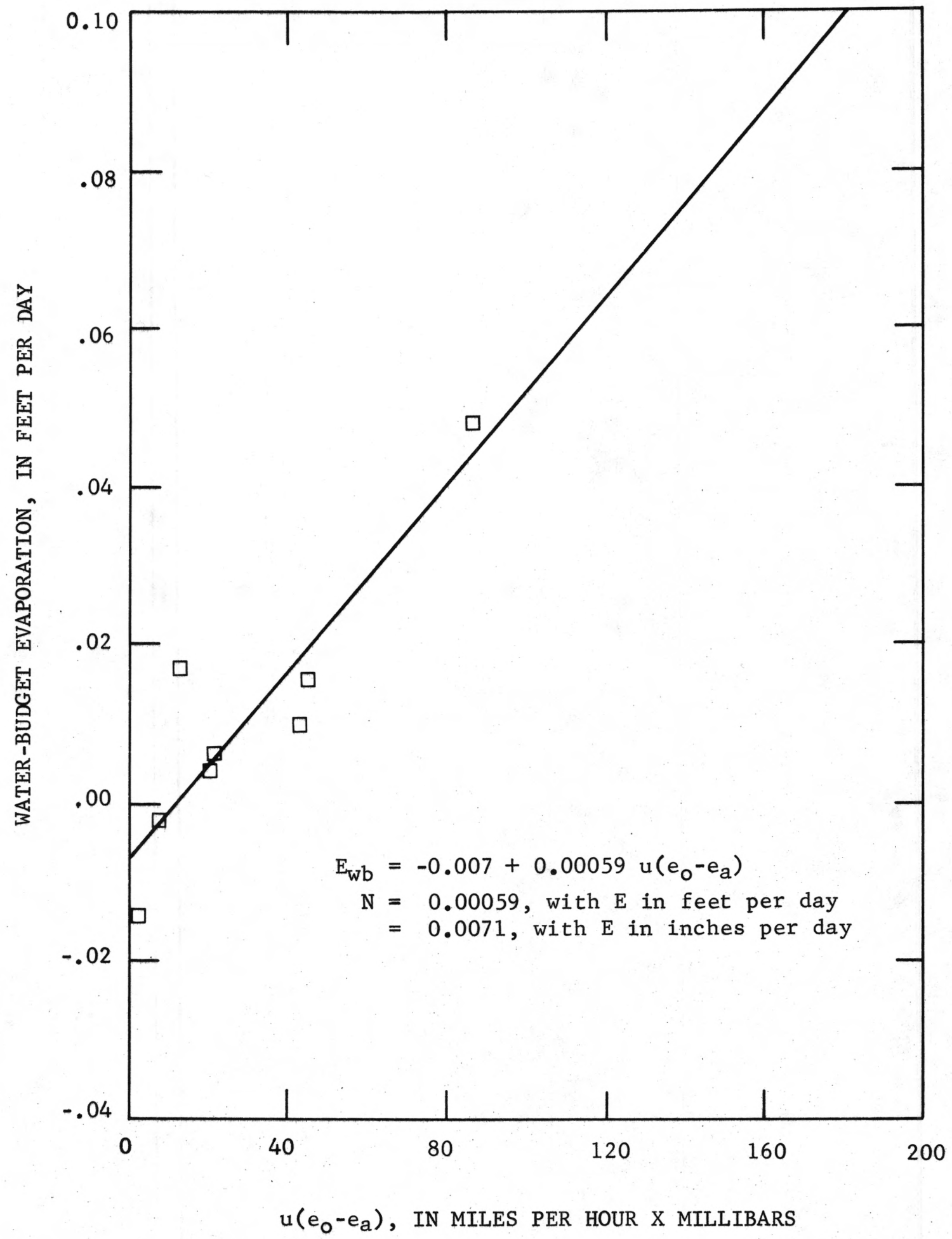

Figure 6.--Relation between water-budget evaporation and the product $u\left(e_{o}-e_{a}\right)$ for periods in 1965, and the computed mass-transfer coefficient. 


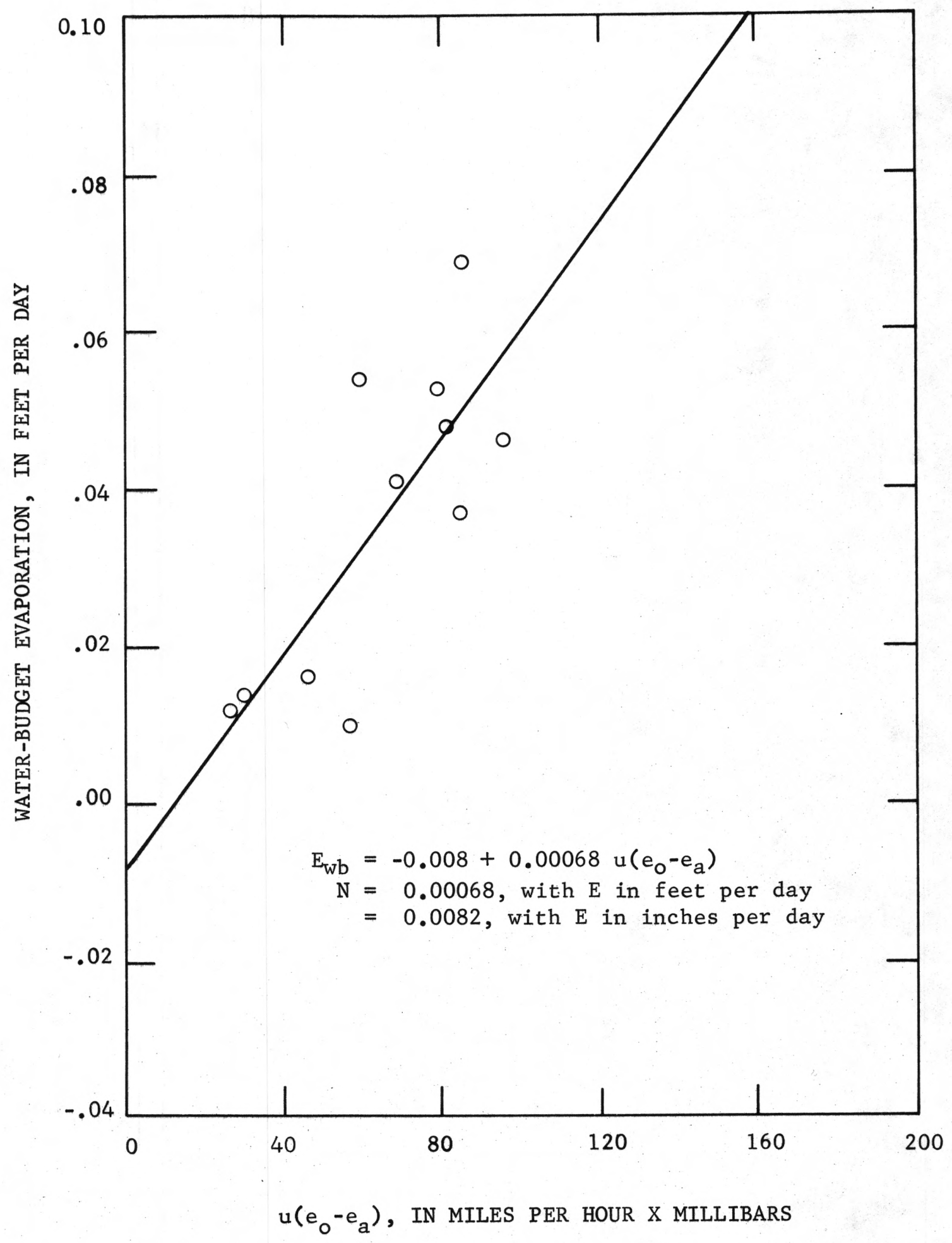

Figure 7.--Relation between water-budget evaporation and the product $\mathrm{u}\left(\mathrm{e}_{\mathrm{o}}-\mathrm{e}_{\mathrm{a}}\right)$ for periods in 1966, and the computed mass-transfer coefficient. 
Tab1e 2.--Evaporation, in inches, from land pan and from mass-transfer method for selected months in 1964

\begin{tabular}{|c|c|c|c|}
\hline & Pan & $\begin{array}{l}\text { Pan ad- } \\
\text { justed } \underline{1} /\end{array}$ & $\begin{array}{c}\text { Mass trans- } \\
\text { fer } \underline{2} /\end{array}$ \\
\hline September 1964 & 5.84 & 4.26 & 12.78 \\
\hline October 1964 & 4.43 & 3.23 & 6.82 \\
\hline Total & 10.27 & 7.49 & 19.60 \\
\hline
\end{tabular}

1/ Using pan-to-1ake coefficient of 0.73 .

2/ Using a mass-transfer coefficient of 0.0072 .

Inaccuracies in the records of inflow and outflow probably are not the cause of a consistently high or low indicated evaporation; however, they probably cause much of the scatter in the plotted points. The inflow and outflow records are generally rated good, which allows for an accuracy of 10 to 15 percent on a daily basis. With an average annual reservoir inflow and outflow of about $170 \mathrm{cfs}$, the daily error in either inflow or outflow could amount to about 25 cfs. On the average, errors for periods longer than a day should be much less than 25 cfs. However, the water budget should reflect a balancing of positive and negative inflow and outflow errors because the discharge rating curves were drawn to balance the defining measurements. Also, the randomness of the 4- to 7-day periods used in the regressions should tend to balance positive and negative differences.

A change in reservoir capacity or an inaccuracy in the reservoircapacity table could account for a consistent positive or negative error in the water budget. However, a resurvey of the reservoir was beyond the scope of this project. Comparison of reservoir-surface area as given in the area-capacity table with that shown on a recent map indicates no noticeable change in reservoir area.

\section{CONCLUSIONS AND RECOMMENDATIONS}

On the basis of this study, the mass transfer-water budget technique for computing evaporation is considered to be impractical for Warm Springs Reservoir. The mass-transfer coefficient of 0.0072 , computed 
from a 3-year regression of the factors $u\left(e_{0}-e_{a}\right)$ and $E_{w b}$, is two to three times as much as expected. Coefficients computed for each of the years of study were two to four times as high as those computed for other reservoirs. This would indicate a varying coefficient from year to year and evaporation two to four times that computed from records at the 1 and pan. However, possible inaccuracies in the inflow and outflow parts of the water budget and the reservoir-capacity table and the unmeasurable effects of bank storage make both the evaporation loss and the computed mass-transfer coefficient uncertain. The location of the raft away from the center of the medium and high reservoir was necessary to allow the raft to remain afloat at minimum pool level, but may have contributed to the lowered accuracy of the results.

If accurate evaporation measurements are desired for this or similartype irrigation reservoirs where inflow, outflow, and change in reservoir storage are large and variable in comparison to evaporation, then the more precise but costly energy-budget technique should be used for about a year to compute accurate mass-transfer coefficients. That method would eliminate the dependence on a water budget of questionable accuracy. Two rafts should be maintained on the reservoir to obtain evaporation data that are representative of high- and low-reservoir pools. When the reservoir is low, one of the rafts would probably have to be moved to prevent its becoming mired in the mud. Separate coefficients might be determined for various pool levels. After the mass-transfer coefficients are computed by the energy-budget technique, the measurements should be continued using the mass-transfer technique. Operation of the mass-transfer equipment should be continued with the same high precision as used in the energy-budget method.

Regardless of which method is used to compute evaporation, extra effort should be made to obtain accurate inflow and outflow records. Also, a check should be made to assure that area-capacity tables for the reservoir are accurate.

Evaporation at the land pan may not necessarily be equal or directly proportional to the evaporation on the reservoir. If a pan is used to estimate lake evaporation, it should be in an environment as similar to that of the lake as possible, and corrections should be made for heat storage and advected energy (Nordenson, 1963, 1965). 


\section{REFERENCES}

Harbeck, G. E., Jr., 1962, A practical field technique for measuring reservoir evaporation utilizing mass-transfer theory: U.S. Geol. Survey Prof. Paper 272-E, p. 101-105.

Kohler, M. A., Nordenson, T. J., and Baker, D. R., 1959, Evaporation maps for the United States: U.S. Weather Bur. Tech. Paper 37, $13 \mathrm{p}$.

Nordenson, T. J., 1963, Appraisal of seasonal variation in pan coefficients: Internat. Assoc. Sci. Hydrology Pub. 62, Gen. Assemb1y of Berkeley, p. 279-286.

1965, Discussion of "Estimating forced evaporation from cooling ponds," by G. E. Harbeck, Jr.: Am. Soc. Civil Engineers Proc., Power Div. Jour., v. 91, no. P01, p. 109-112.

Whistler, J. T., and Lewis, J. H., 1916, Malheur and Owyhee projects: U.S. Reclamation Service Oregon Coop. Work, 201 p. 
